\title{
THE STATE OF CONSUMPTIVE WATER USE ACCOUNTING AND IMPACT
}

ASSESSMENT

Spencer Meriwether Ingram

Powhatan, Virginia

B.S. Engineering Sciences, University of Virginia, 2008

A Thesis presented to the Graduate Faculty of the University of Virginia in Candidacy for the Degree of Master of Arts

Department of Environmental Sciences

University of Virginia

August, 2010

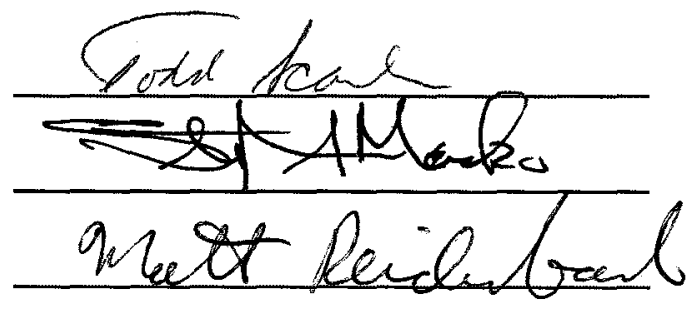




\begin{abstract}
Transportation innovations in the early $19^{\text {th }}$ century and inter-continental price convergences affecting domestic markets and resulting in political protections marked the unprecedented beginning of globalization (O'Rourke, 2000). As a consequence, pollution, environmental degradation, and economic and social disparities are no longer geographically independent.
\end{abstract}

Water use involves complex political, economical and social issues that will need to be addressed as increased demand and environmental change increases water scarcity and quality world-wide. Water Footprinting emerged in the past decade as an accounting system for consumptive water use. However, it is unclear how volumetric reporting provides a comparative tool for decision making that promotes the transition towards sustainable, fair and efficient use of fresh water resources globally. Although water use and the subsequent impacts may be regional or catchment specific, I will argue that consumption impacts are actually a global phenomenon that requires a universally comparable utility for efficient management to protect the economic, social and environmental interests of the global community.

This paper investigates the state of water footprinting as a candidate for consumptive water use management strategy and then introduces life cycle assessment as a model utility for impact assessment. 


\section{Acknowledgments}

To my mother who has repeated the words, "is your thesis done yet?" more than anyone on Earth.

A great deal of thanks is owed to my committee members for their patience and taking the time to evaluate this paper. 


\section{Personal Motivation}

My interest in water resources grew from working on a small hydroelectric plant as an undergraduate engineering student. Following completion of the project, I turned my engineering coursework to water resources engineering and supplemental courses in environmental sciences. My curiosity drove me to explore the environmental sciences from a broad technical perspective in the Master of Arts program at the University of Virginia. I found that I was most interested in design solutions for environmental issues in production-consumption systems. This paper explores the challenges facing consumptive water use through accounting and impact management schemes. It is my career goal to continue pursuing science and engineering with application to production-consumption systems for improved quality of life and environmental value. 
Table of Contents

$\begin{array}{ll}\text { Signatures Page } & \text { (i) } \\ \text { Abstract } & \text { (ii) } \\ \text { Acknowledgments } & \text { (iii) } \\ \text { Personal Motivation } & \text { (iv) } \\ \text { Table of Contents } & \text { (v) } \\ \text { List of Figures } & \text { (vii) } \\ \text { List of Tables } & \text { (viii) }\end{array}$

Chapter 1 Introduction

Goal and Scope

1

2

Chapter 2 Introducing the Water Footprint Concept 6

History 6

Assessment Boundaries 9

Defining Scarcity 12

Sustainability Assessment 13

Chapter 3 Measuring a Water Footprint 15

Blue $\quad 15$

Green 17

Grey 19

Footprinting a Product 23 
Chapter $4 \quad$ Challenges in Water 28

Volume vs Value $\quad 28$

Market Value 32

Environmental, Social and Economical Perspectives 34

Environmental 38

Social $\quad 38$

Economical $\quad 44$

Universality $\quad 47$

Chapter 5 Understanding Life Cycle Assessment 50

History $\quad 50$

LCA Framework $\quad 52$

Limitations $\quad 56$

$\begin{array}{lll}\text { Chapter } 6 & \text { Merging Concepts } & 61\end{array}$

Appeal of Carbon footprinting 62

LCA advances in freshwater consideration $\quad 64$

Conclusions $\quad 65$

$\begin{array}{ll}\text { References } & 69\end{array}$ 


\section{Figure pg Description}

Figure (1) 2 Industrial water use globally and by country income.

(UNESCO, 2003)

Figure (2) 36 Crop water productivity simulated for wheat in 2000.

(Yang, 2007)

Figure (3) 37 Dependence on cereal imports as a function of water availability in volume per capita. (Yang, 2007)

Figure (4) 41 Industrial water use efficiency per capita as measured by economic value added compared to industrial water use in volume per year (UNIDO, 2003)

Figure (5) 55 A Life Cycle Assessment between paper and plastic grocery bags revealing the advantages of plastic. (Graedel, 1998)

Figure (6) 59 Correlation between the discriminate value of LCA results and the scientific reliability. (Vezzoli, 2008) 


\section{List of Figures}

\section{Figure pg Description}

Table (1) $31 \quad$ Comparison between the volumetric water footprint and stress

weighted footprint revealing uncertainty in reporting a volume. (Ridoutt, 2010) 
Introduction

Owing to unique physical properties, water is a valuable, ubiquitous agent in industry, agriculture and human health. Water is used to grow food, provide sanitation, heating and cooling, incorporated into products and transformation of energy in the production of electricity to name a few broad applications.

Twenty percent of the world's freshwater consumption is from industrial practices and seventy percent from agriculture. An increase in income coincides with shifting water use from agriculture to industry. Furthermore, market globalization has moved labor industries from high to low income countries resulting in increased water demand beyond available resources (UNIDO, 2003). The unequal distribution of water resources combined with industrial impacts and agricultural demand results in a poorly managed global necessity. 

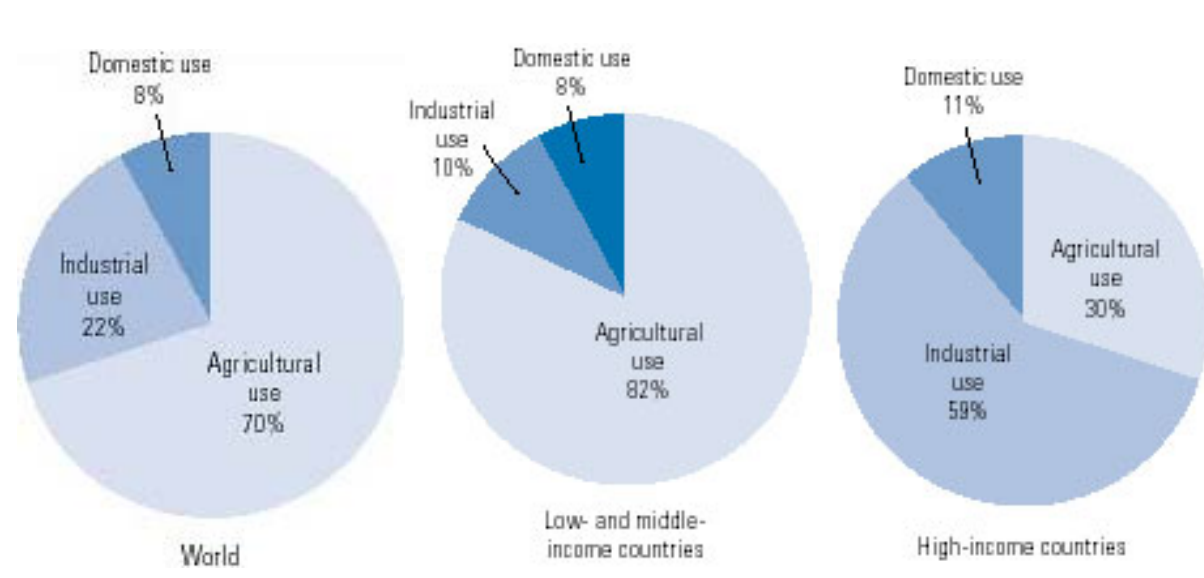

Figure 1. Agriculture is the dominant global water consumer. High income countries use more water resources in industrial applications as a result of larger economic gains in industrial products and services. (UNESCO, 2003)

In places or times of abundance, water is easily perceived as in exhaustible by its renewable nature in the hydrologic cycle. However, water availability is limited at the global scale or under pressure from high consumption rates. Management of economic, environmental and social impacts of water availability would benefit from a holistically prescribed accounting and impact assessment utility.

\section{Goal and Scope}

Transportation innovations in the early $19^{\text {th }}$ century and inter-continental price convergences affecting domestic markets and resulting in political protections marked the unprecedented beginning of globalization ( $\mathrm{O}^{\prime}$ Rourke, 2000). As a consequence, pollution, environmental degradation, economic and social disparities are no longer geographically independent. As a globally scarce 
resource, water demands a global management system protecting the economic social and environmental interests of the global community. In the early 1990's, environmental impact assessment for manufacturing known as life cycle assessment (LCA) became widely adopted. LCA, however, did not account for consumptive water use. Over the next decade, the virtual water concept arose independently of LCA in an effort to quantify of water resources consumed in manufacturing and agriculture and subsequently where these products were transported. In 2002, the water footprinting concept was published to address continuity between virtual water studies and to yield new insights on consumptive water use by businesses, consumers and geographic location (Hoekstra, 2009).

This paper investigates the state of water footprinting as a candidate for consumptive water use management strategy and then introduces life cycle assessment as a model utility for impact assessment. Although water use and subsequent impacts may be regional or catchment specific, I suggest that consumption impacts are actually a global phenomenon that requires a universally comparable utility for efficient management. For example, the geographically deliberate execution of industry can mitigate opportunity costs for water resources by redistributing the available resources more efficiently. 
This is a complex issue concerning the societal impacts of water use, understanding of environmental impact, market forces and implications for governing and policy roles. I will set the stage for these issues by addressing a frontier of research with-in interdisciplinary sciences that contribute to the complex and often subjective issue of water management.

I will first introduce the water footprinting concept and basic practice behind the system. Next I will discuss perspectives on water's role in the environment, society, politics and economics. This complexity reveals some of the challenges for water footprinting and the implications for comparative reporting. For example, how to report water footprints in a dependable and universally comparable standard is a current challenge (Ridoutt, 2010; Milà, 2009; Pfister 2009; Ridoutt, 2009, Warner, 2007). Finally, I will review life cycle assessment as a model utility for addressing some of the challenges in consumptive water use assessment. I will conclude by introducing recent advances and future challenges for a consumptive water use assessment.

I will use the term water to describe, exclusively, freshwater resources. While salt water is abundant on Earth, its utility is limited. The conversion of salt water to fresh water is energy intensive and while it may contribute to freshwater supply, the subject of this paper is to explore freshwater consumption in products and services as applied to an accounting and impact assessment 
system. In addition, products will be defined as durable and nondurable goods and services. 


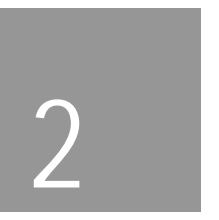

Introducing the Water Footprint Concept

Water management is no longer a catchment scale issue. It is complexly tied to the economy, environmental sciences, and local, regional and global communities where the consumers, scientists, businesses and policy makers all play a role. This level of complexity introduces an array of challenges for water resource management including spatio-temporal scale in accounting, quality standards, scarcity and impact assessment, comparative applications and corporate and national social responsibility. Despite these challenges, scientists have in recent years devised methods to quantify water use in an effort to learn about the nature of water consumption patterns and provide management insight.

History

Water footprinting accounts give spatiotemporally explicit information on how water is appropriated volumetrically for various human purposes. The method links consumption with geographical distribution and supports discussion on water use policy and the environmental, social, and economic 
impacts within supply chains and trade systems (Yang, 2007; Hoekstra, 2009). How is this different than water withdrawal measures? The water footprint accounts for withdrawal, or direct use, but also indirect use as aggregated withdrawals over supply chains. The water footprint is used to investigate withdrawal in terms of consumption and by water discharge. The discharged water is known as grey water and is a volumetric account of the pollution.

Allen (1996) coined the term virtual water in application to agricultural trade systems where water scarce nations import water intensive crops they otherwise would not be able to produce. Virtual water soon expanded in scope to describe the water required for production of commodities and services. Terms like embedded, embodied, exogenous or shadow water became known as virtual water and began drawing attention from the public and water resource scientists and policy makers. A decade later, Yang (2007) explained how virtual water "concerns the water scarcity, food security and trade nexus in the context of natural, socioeconomic and political systems in regions, countries and the whole world." To address these concerns, the term water footprint was introduced by Hoekstra (2002) and has since gained attention of the media, scientists and international agencies (Pearce, 2008; Hoekstra et al. 2009; UNESCO, WWF, Coca Cola). 
Water footprinting is considered a multidimensional indicator for water use since it indicates the type of water consumed and may be applied to a scope broader than virtual water. A water footprint best describes a person, business or nation as a term for consumption and water borne pollution dilution. When it comes to supply chains or trade systems it is accurate to use virtual water to describe the flow or exchange of water. Virtual water flows in a supply chain culminate in the water footprint of a specific product; measurable down to the brand level, but not without challenges (Ridoutt, 2009). There is a lack of correspondence between water footprints as a result of inconsistencies in coverage, aggregation, period considered and source of data (Yang, 2007). Hoekstra, (2009) addressed inconsistencies by publishing the Water Footprint Manual; State of the Art as a guide for measuring footprints and attempts to define footprints conditionally by intended uses.

The water footprint has potential to reveal overexploitation of water bodies and groundwater resources. The footprint can forecast declining resources available to ecosystems and potable water for human health. Governing bodies may use water footprinting as a tool for developing policy measures. Water footprinting can illustrate the water intensive aspects of supply chains to help reduce costs within industries. There is also great marketing potential in an ever growing consumer conscience towards corporate 
responsibility. However, adoption by businesses and consumers will require an intuitive understanding and dependable reporting of what the water footprint means. Currently, it is difficult to distinguish between the impacts of two volumes and therefore difficult to understand how a water footprint may be applied to comparative analysis. In fact, water footprints are "not a measure of the severity of the local environmental impact of water consumption and pollution. They can feed the discussion about sustainable and equitable water use and allocation and also form a good basis for a local assessment of environmental, social and economic impacts"(p11 Hoekstra, 2009). Locally and globally the economy is, now more than ever, tied to social and environmental impacts. The organization and practices along a supply chain strongly influence water consumption and pollution. The value applied to water use and the corresponding severity of impacts depends on factors that may be dependent how space and time are truncated.

\section{Assessment Boundaries}

Supply chains appear less as chains of resources and rather as web of transfers. The complexity is not without efficiency, but does produce a challenge when determining where to truncate the water footprinting assessment. This is a common issue faced by carbon footprinting and life cycle assessment. However, 
unlike these two accounting systems, "no general guidelines have been developed yet in the field of water footprint accounting, but the general rule is: include the water footprint of all processes within a production system that 'significantly' contribute to the overall water footprint" (p12 Hoekstra, 2009). Subjectively defining significance reinforces the need to establish guidelines. If the goal is to develop a comparable consumptive use reporting scheme, then these guidelines will be necessary to promote equitable accounting. While defining significant contributions is subjective, as long as the same truncation guidelines are used than comparable reporting may be obtained.

It is recommended that labor not be included in accounting (Hoekstra, 2009). People require water as part of food, clothing and shelter in order to survive and be valuable as labor. The inclusion of labor would result in double counting as laborers are also consumers of the goods and services produced by labor, thus creating a cyclical accounting problem. Addressing the water footprint of labor is also difficult in that there are widely varying consumer water footprints. Labor might also raise social impact issues that are not part of water footprint but are considerable when assessing the indirect practices associated with consumptive water use. While impact is not part of the water footprint, concerns may still be identified through the water footprinting process. With a 
value added scheme, concerns are not only identified but held accountable and remediated.

Issues of transportation and energy are also typically left out of the equation unless, as Hoekstra (2009) suggests, those constituents are bio-fuel heavy. Water footprint accounting is concerned solely by processes with significant contributions of water where transportation is often not a major consumer of water resources. As fuel and energy markets experience increased environmental scrutiny, a demand for water use comparisons may emerge where a lack of consistent guidelines and absence of a valuation scheme would be easy targets for criticism.

Since volume is the base metric, water footprinting only accounts for volumetric opportunity costs. Water footprinting is not intended then to evaluate the value of various water consumption activities. This is not to suggest that a measure of volume does not provide insight. When one starts to look at the water use along supply chains, the indirect use and aggregated volume of water consumption offers a holistic perspective on global water demand. Consumptive use of a water reservoir is limited, at the least, by the total volume of that reservoir. Therefore, a volumetric account of consumption may serve as an indicator (not a measure) of stress on a reservoir. 
Even if water footprinting established definitive truncation guidelines, further assessment complications arise with the availability of data. Data are limited due the lack of need for measuring water consumption in many practices. When data is available it measures water withdrawal and not consumptive use. It is important to distinguish between water withdrawal and consumptive use. Withdrawal from a reservoir does not describe whether the water evaporates, is incorporated in the product, returned to the reservoir or transferred to another reservoir and at what time. Water footprinting promotes the spatial and temporal signature in lost return flows when data is available.

\section{Defining Scarcity}

The value of water varies with scarcity as a function of geographic climate, management and access. However, water use is mostly excluded in the cost of a product due to a commons approach to water management and low market values. Scarcity, as defined by a given location and time, will illustrate opportunity costs and influence water allocation based on a value metric and impact reduction. Since the water footprint currently does not account for impact assessment the opportunity costs are evaluated only as a volumetric comparison. The implicit assumption with raising water use awareness is that by reducing consumptive use there will be more water available for some 
alternative use and yet with water footprinting it is unclear that this is the case (Ridoutt, 2010). In addition, variations are rather large in the estimated virtual water flows at the global level as well as at the country level among different studies (Yang, 2007). Inconsistency in virtual water content, the spatiotemporal coverage, truncation and data sources are a major obstacle in accurate reporting (Yang, 2007).

\section{Sustainability assessment}

Sustainability is an ambiguous term that needs spatial, temporal, scale and motive definitions. It is necessary to ask what needs to be sustained, where, for how long and how broad. Defining the terms of sustainability is not an easy task as conflicts quickly arise between interest groups. Economic, social and environmental interests are inherently connected but often in conflict. The conflict arises due to limited resources, space, time and differing perception of best practices.

It is easy to imagine a scenario in which an agricultural product is harvested for biofuel production. This crop withdraws from a limited water resource that might otherwise be used for another industry. Fertilizer pollution impairs the surface water reservoirs, changes the land use and ultimately does 
not directly provide food for people. However, this agricultural product demands a greater market price, provides local jobs and may promote additional social programs in the area. This hypothetical situation illustrates conflicts between economic, social and environmental interests while still portraying opportunity for improvements in each.

How can one make decisions for best practices when the economic, social, and environmental components are connected by often in conflict? By investigating water footprints at local levels, inefficiencies and negative impacts might be relieved by scaling water use up to the global level. This is not without challenges that rest on national sovereignty and the pursuit of purely economic gains in global markets.

I will discuss in chapter two how water footprints are calculated by their Blue, Green and Grey constituents, provide an example for footprinting a product and discuss obstacles in measuring a water footprint. 


\section{Measuring a Water Footprint}

While blue and green water resources are interconnected in the hydrologic cycle, they represent two different reservoirs with distinct value and opportunity costs. The grey water footprint is a measure of anthropogenic pollution in terms of dilution volumes for ambient water quality standards. By measuring the blue, green and grey water footprints as separate reservoirs, the anthropogenic influences are more accurately observed. Combined, these component footprints equal the total water footprint.

Total Water Footprint $=$ Blue Footprint + Green Footprint + Grey Footprint

Blue

Blue water is the fresh surface and groundwater resources attributed to consumptive use where the water evaporates, is incorporated into the product, does not return to the same catchment or has a temporal discontinuity, such that water is withdrawn in one period and returned in another. Blue water does not account for salt water reservoirs as salt water has little economic value due the energy required to produce fresh water from salt water. 
Blue water use is often responsible for reducing machinery temperature, washing materials, or physical incorporation into a product. The most obvious examples of incorporation are in liquids such as detergents and soft drinks.

However, there are many other products that consume water in the manufacturing or agricultural process. The agricultural use of blue water includes diverting surface water to irrigation and pumping groundwater for crops.

Why are we concerned about water use when water a renewable resource? Water might evaporate or flow to the ocean, but it comes back somewhere else in the cycle. While this is true, it also describes why availability is often limited through rates of replenishment. Blue water footprinting helps illustrate the available water resources for municipal water supplies, agriculture and industry within a given reservoir and time. However, this accounting does not include the natural systems that rely on these reservoirs. While the data on natural system water use is available, it often represents little economic value with respect to other applications for water.

A blue water footprint is the sum of consumed blue water resources described as the following: Blue Water Footprint = BlueWaterEvaporation + BlueWaterIncorporation + LostReturnflow 
Lost return flow differs from incorporation and evaporation in that it refers to blue water no longer available within the same period or catchment. The blue water footprint can be further divided into the surface water, renewable groundwater and fossil groundwater sources; referred to as light-blue, dark-blue, and black water footprints. These reservoirs differ greatly in recharge rates, cost of access, and water quality. These considerations are not reported in the blue water footprint. Instead, a volume that is often attributed to a per unit time or per unit product is calculated.

Blue water resources are recharged by precipitation. However, not all precipitation is accessible as blue water. The precipitation that evaporations from plants, or resides as soil moisture is considered green water.

Green

The green water footprint is an account of the anthropogenic use of rainwater that is intercepted by plants or does not recharge groundwater or surface water. As soil moisture, this water evaporates or transpires through crops. Soil moisture has a limited use compared to blue water resources and is therefore treated as a different reservoir.

There are however instances where these reservoirs overlap. Irrigation by blue water that becomes green water is considered blue water consumptive use 
and is attributed to the blue water footprint. Secondly, rainwater harvesting transfers potential green water to a blue water reservoir. This is considered part of the blue water footprint as runoff. Green water resources are not easily transferable and these reservoirs and fluxes are difficult to quantify as a result of the technical complexity.

Green Water Footprint $=$ GreenWaterEvaporation + GreenWaterIncorporation

When calculating blue and green footprints, the water use for operation of a product, a dishwasher or toilet for example, is not recommended as part of the water footprint of the product, but rather, the water footprint of the consumer or building (Hoekstra, 2009). For many use-stage water intensive products, there are incentives (LEED) and marketing (Energy Star) strategies that seek to economically reduce water use. The product level footprint ideally provides insight for consumer choice. Comparing the use-stage of water footprints may be a valuable indicator of water demand based on consumer behavior or building design strategies.

In both blue and green water footprints, there may be water that is returned to the environment either as runoff or industrial effluent. This water may contain pollutants which reduces the water quality in the output body. This returned water is called grey water. 
Grey

The grey water footprint describes the concentrations of pollutants allowable by water quality standards defined for a given reservoir. The grey water component is expressed as a dilution volume requirement. The notion of a dilution effect is in accordance with most water quality regulations. Grey water is intended to report on water requirements to assimilate pollutants into a body of water. Reducing pollutants is a preferred treatment, but water footprinting is intended to report on volumetric use of water.

The term grey water footprint was introduced in 2008 by Chapagain (2008) and may be applied to point source pollution and potential runoff or groundwater pollutants. Grey water footprints also disregard the decay of pollutants over time. Again, water footprinting is concerned with volumes of water, not specific quality or value, and illustrates a challenge for industrial adoption and enforcement.

The grey water footprint is reported in volume per unit time and derived by dividing the pollutant load ( $L$, mass/time), by the difference between the maximum allowable pollutant concentration $\left(C_{\max }\right.$, mass/volume) for ambient water quality, and the natural concentration ( $C_{\text {natural, }}$ mass/volume). 
The grey water footprint uses the natural concentration as the condition that would occur without anthropogenic influences. The natural concentration is used as a reference to indicate the assimilation capacity of receiving body of water. An actual concentration within a reservoir changes through time and it is therefore important to evaluate the pollutant impact as a singular input. Also, we know that this grey water reporting suggests the minimum required dilution volume per pollutant load; quite often the dilution volume will be larger.

Most often, pollutants in industry are discharged in solution. If the pollutant load is part of an effluent discharge (Effl, volume/time), then specific pollutant loads are determined by multiplying the effluent discharge by the difference between the concentration of specific pollutants within the effluent $\left(C_{\text {eff }}\right)$ and the natural concentration $\left(C_{\text {natural }}\right)$ in the receiving body.

$$
\text { Grey Water Footprint }=\text { Effl }\left(C_{\text {eff }}-C_{\text {natural }}\right)\left(C_{\max }-C_{\text {natural }}\right)^{-1}
$$

Water pollution also concerns anthropogenic influences on water temperature. The grey water footprint is calculated similar to a chemical pollutant load with temperature $\left(T,{ }^{\circ} \mathrm{C}\right)$ in place of concentration.

$$
\text { Grey Water Footprint }=\text { Effl }\left(T_{\text {effl }}-T_{\text {natural }}\right)\left(T_{\max }-T_{\text {natural }}\right)^{-1}
$$

Often times local temperature regulations are not available and in such a case, Hoekstra (2009) recommends a default 3 degrees Celsius. 
From these equations, it is simple to derive a critical pollutant load ( $\left.L_{c r i t}\right)$ by replacing grey water footprint (volume/time) with the discharge for the water body ( $Q$, volume/time). This equation describes the critical mass of pollutant that can be assimilated in a given period of time.

$$
L_{\text {crit }}=Q\left(C_{\max }-C_{\text {natural }}\right)
$$

The grey water footprint functions on three variables; mass, volume and time. While reducing pollution mass is certainly the most ethical endeavor, a grey water footprint may also be diminished by reducing the time over which discharge occurs or by adding water to the volume of the effluent. However, water volume added is often withdrawn from the receiving body and therefore nullifying any affect on total reservoir volume. When the effluent concentration is equal to the natural concentration, the grey water footprint is zero. This means the pollutant concentration never changed. When the effluent concentration is greater than the natural concentration the assimilation capacity of the water body is reduced. This does not mean that the effluent fails to meet water quality standards for a particular pollutant. Sometimes effluent concentration can be less than the natural concentration. This effluent has the effect of reducing the ambient concentrations by cleaning the water body. It is unusual, but a case may 
exist when maximum concentration is equal to natural concentration and therefore permissible effluent concentrations are less than natural conditions. Maximum pollutant concentrations are derived from ambient water quality standards. These standards vary between water bodies and between other standards such as drinking water, irrigation quality, or emissions. The selection of standards and specific pollutants is important to the application of the grey water footprint. Water footprinting does not yet provide recommendations for specific applications of grey water footprinting. Hoekstra (2009) acknowledges the ambiguity of defining grey water footprints by explaining that the level of reporting is determined by the goal of the water footprint investigation. "If one is interested in the pollutant-specific grey water footprints, one can of course report those values separately. For formulating response measures targeted at specific pollutants, this is of course very relevant. For the overall picture of pollution, however, showing the grey water footprint for the critical substance is good enough" (p24, Hoekstra, 2009)

The division of water resources into blue, green and grey components helps to illustrate significantly different implications for transport, recharge rates and environmental impact and opportunity costs. But to apply water footprinting with dependable and comparable results, standard metrics must be adopted. 
Footprinting a Product

While water footprinting may be applied to individuals, business or nations, I am focusing on the application for production of agricultural and manufactured goods and services.

Water footprinting offers a geospatial context. Geospatial referencing is a growing transparency trend in manufacturing. Product origin and the transportation energy in supply systems are becoming part of the consumer conscience. The geographic references effectively help determine spatially variable environmental and social practices with subjectively applied values. These values are important to the growing concern for access to fresh water resources, rampant consumerism and energy demand. However, valuation is not part of the water footprinting mantra and determining credible value for social and environmental impacts is recommended before water footprinting can be applied to the product brand level (Ridoutt et al., 2009). Product water footprinting has the potential to support environmental declarations and corporate sustainability in product lines.

One challenge to water footprinting a product is the variance in methodology. The accounting process, assumptions and reported units are not formally adopted and pertain most to a specific investigation. This results in a 
lack of correspondence between water footprints. These variances aside, water footprints for production systems follow two approaches. The chain summation approach describes systems with a single output. The water footprint is determined by adding the relevant process water footprints in a production system. Few production systems multiply processes that result in only one product. Most supply chains are more like supply webs. When processes result in multiple products, a step-wise accumulation approach is used.

With step-wise accumulation, a complex web of inputs and outputs can be evaluated. The summation of input product water footprints (WFprod[i]) is distributed over the corresponding output products by the product fraction $(f p[p, i])$. If output products have a process with a water footprint, this account (WFproc $[p])$ must be added.

$$
W F_{\text {prod }}[p]=\left(W F_{\text {proc }}[p]+\sum_{i=1}^{y} \frac{W F_{p r o d}[i]}{f_{p}[p, i]}\right) \times f_{v}[p]
$$

(Hoekstra, 2009)

The recommended water footprint reporting is in volume per mass. The product fraction distributes the input product footprints over the individual output products as a ratio of output product mass obtained per quantity of input product mass. The remaining function, $(f v[p])$ is the value fraction that serves as 
a ratio of a specific output market value (price/units or price per mass) multiplied by that output's mass or units and then divided by the aggregated market value of all the output products sharing the same input products. The terms price $[p]$ and $w[p]$ represent the price of the product (monetary unit/mass) and output product (mass) respectively.

$$
f_{v}[p]=\frac{\operatorname{price}[p] \times w[p]}{\sum_{p=1}^{z}(\operatorname{price}[p] \times w[p])}
$$

(Hoekstra, 2009)

Despite the potential challenges measuring market value and accounting for fluctuating market value, the value function is simple to apply.

Conceptually, however, the value function appears counter intuitive. If one reviews the sugar beet example from Hoekstra (2009), the production of sugar beets in Valladolid, Spain is reported with a green water footprint of $53 \mathrm{~m}^{3} /$ ton. Sugar beets are then processed into raw sugar, molasses, and beet pulp used in animal feed. The $53 \mathrm{~m}^{3} /$ ton green water footprint for sugar beets is distributed over the three output products, refined sugar, beat pulp and molasses. For refined sugar, the value fraction is reported at 0.89 (US\$/US\$). This indicates that the product of sugar mass produced and market price are considerably greater than that of beet pulp and molasses. The remaining value fraction for either beet 
pulp or molasses would be less than $0.11 \mathrm{US} \$ / \mathrm{US} \$$. As a result the water footprint for either beet pulp or molasses is reported as less than ten percent of the combined distributed input footprint and output process footprint.

This seems counter intuitive because a small market price would suggest less economic value for corresponding water use. Sugar, with a high output mass and market value will report a larger water footprint than beet pulp or sugar, but has greater economic value. One would think that a value function based on market price would portray higher price as a higher value per volume of water used and therefore reduce the water footprint comparative to additional outputs.

In the Valladolid sugar beet example, the output products illustrate an example where the maximum use potential of a sugar beet results in three products; sugar, beet pulp and molasses. A condition does not exist where one output product is selected over another output product. However, other input products (corn, oil, trees) exhibit many competing types of output products. With an input product of this type, an opportunity cost arises between selecting output products. The opportunity cost may be measured by volume of water in the water footprinting example. However, by using the value function, a market price appears to distort the volumetric reporting and as a result may lend to criticism when promoting less water use. 
Water footprinting has the potential to produce a valuable system of water accounting with implications as a useful tool in manufacturing, agriculture, energy industries and governing policy. I will discuss in chapter three the environmental, social, economic and political impacts regarding consumptive water use and I will further discuss some of the challenges for applying water footprinting to a comparative water management scheme. 
Challenges in Water Footprinting

Volume vs Value

The water footprint concept was introduced in 2002 and is largely influenced by the Water Footprint Network and the United Nations Educational, Scientific and Cultural Organization (UNESCO). The Network's mission is outlined as, "promoting the transition towards sustainable, fair and efficient use of fresh water resources world wide by 1) advancing the concept of the 'water footprint', a spatially and temporally explicit indicator of direct and indirect water use of consumers and producers, 2) increasing the water footprint awareness of communities, government bodies and businesses and their understanding of how consumption of goods and services and production chains relate to water use and impacts on fresh-water systems and 3) encouraging forms of water governance that reduce the negative ecological and social impacts of the water footprints of communities, countries and businesses" (WFN).

This is certainly a noble and mission that I respect. However, it is unclear to me how the water footprint will reduce negative ecological and social impacts when water footprinting, "is not a measure of the severity of the local 
environmental impact of water consumption and pollution "(p11 Hoekstra, 2009). Water footprint's volumetric reporting method provides valuable insight to water demand, virtual water trade and other instances where a volume is best reported. When considering impact assessment, a volume measurement is only a starting point. The impacts associated with a volume of water use will vary from geographic region, time of use, and type of use. Therefore the value of a volume of water is not universally equal. Consider the following example of two water consumption processes. Bradley Ridoutt of CSIRO (Commonwealth Scientific and Industrial Research Organization) Sustainable Ecosystems, calculated and compared the water footprints of Dolmio® pasta sauce and Peanut M\&M's ${ }^{\circledR}$ (both products of Mars Inc. and manufactured and consumed in Australia) (Ridoutt, 2010).

\begin{tabular}{lcc}
\hline Ingredient & $\begin{array}{l}\text { Volumetric water } \\
\text { footprint (1) }\end{array}$ & $\begin{array}{l}\text { Stress-weighted } \\
\text { water fotprint (1) }\end{array}$ \\
\hline Dolmio ${ }^{\star 0}$ pasta sauce & & \\
$\quad$ Tomato products & 149.9 & 133.9 \\
Sugar & 22.9 & $<0.1$ \\
Onion & 12.0 & 1.8 \\
Garlic & 5.9 & 0.1 \\
Minor ingredients & 3.3 & 1.9 \\
Peanut M\&M's & & \\
Cocoa derivatives & 690.1 & 4.1 \\
Peanuts & 140.2 & 1.1 \\
Sugar & 135.1 & 0.9 \\
Milk derivatives & 133.6 & 5.3 \\
Palm oil derivatives & 27.3 & $<0.1$ \\
Minor ingredients & 17.8 & 0.2 \\
Tapioca starch & 7.9 & 0.5 \\
\hline
\end{tabular}

Table (1) Comparison between the volumetric water footprint and stress weighted footprint revealing an uncertainty in the reliability of volumetric reporting when it comes water reduction or reallocation schemes . (Ridoutt, 2010) 
The water footprint of $575 \mathrm{~g}$ Dolmio pasta sauce is one sixth that of $250 \mathrm{~g}$ Peanut M\&M's (the functional unit was defined as the stock keeping unit, 575g jar of Dolmio and a 250g bag of Peanut M\&M's). "It is not clear what good would result from choosing a product or production system on the basis of it having a lower water footprint. Indeed, a product with a lower water footprint could be more damaging to the environment than one with a higher water footprint depending upon where the water is sourced" (p114, Ridoutt, 2010).

Ridoutt's (2010) suggestion is to provide a water stress characterization that accounts for the impacts on scarcity. This was accomplished by identifying, as specifically as possible, the source locations for all consumptive water use in the product supply chains. The water consumption at these locations was then multiplied be the relevant characterization factor derived from the Water Stress Index (WSI) developed by Pfister (2009). As a result, the re-calculated stress weighted water footprints indicate that Dolmio pasta sauce is more than ten times likely to attribute to water scarcity than M\&M's, Figure 2 (Ridoutt, 2010).

One implicit assumption of measuring consumptive use is that by foregoing consumption the water footprint volume is available for some alternative use. This is not always true. For the tomatoes in Dolmio pasta sauce, the irrigation water from ground water and river sources would be available for 
an alternative use or contribute to environmental flow. The tomato plants in Dolmio are grown in hot, dry climates (Murray Darling Basin, Victoria, Australia and San Joaquin Valley, California) where scarcity is a concern. In the case of Peanut M\&M's with chocolate sourced from indigenous understory cacao trees, the green water evaporation is not transferable in the absence of production. Between two equivalent products, a larger water footprint from a location without water scarcity may be preferable to a smaller footprint from a location of high water scarcity (Ridoutt, 2010). The Peanut M\&M's may have a larger water footprint, but the opportunity cost on scarcity alone of growing tomatoes as opposed to harvesting cocoa is a concerning issue. "This illustrates the point that different kinds of water consumption should not be simply added to produce a water footprint because the opportunity costs and the impacts associated with each form of freshwater consumption differ," (p115, Ridoutt, 2010). "It is therefore not surprising that many have viewed the popularization of the water footprint with concern because of the potential for misinterpretation and confusion," (p114, Ridoutt, 2010).

Water valuation is a complex challenge rising from the diversity of uses, indirect ecosystem functions, difficulty quantifying environmental impacts and the inherent subjectivity involved. Indirect functions include the aquatic ecosystems in flood control, groundwater recharge, shoreline stabilization, 
nutrition cycling, water purification, ecological preservation and recreation. While impact analysis is a challenge, scientists like Ridoutt are working on systems that will potentially alleviate water scarcity, reduce environmental degradation and steer policy.

One of water footprinting's strengths is to increase popularity by public adoption and advocacy. The popularity of a concept greatly influences manufacturing and services through consumer driven economies. What water footprinting does well is to globalize perspectives on water use and trade. In similar fashion, carbon footprint's adoption is the ease of understanding and normalized reporting (Ridoutt, 2009). Carbon footprints are reported in comparable units where greater GHG (green house gas) emissions correlate to greater global climate change impact, regardless of emission location. While consumptive water impacts vary in time and location, it is not impossible to imagine a system to standardize measurement for impact analysis.

Market Value

One opportunity for water valuation is by price index. The market cost of water generally does not correspond well with the social and environmental impacts and does not correspond well with supply and demand economics. "Generally the price paid for water is far below the real economic cost. Most 
governments subsidize water supply on a huge scale by investing in infrastructure like dams, canals, distribution systems, and wastewater treatment [and] water users generally do not pay for the negative impacts that they cause on downstream people or ecosystems" (p64, Hoekstra 2009). Water in agricultural products is inexpensive due to subsidized food-grains and trade below production costs (Roth, 2007).

Without a direct link to costs and impacts through supply and demand, the price of water is negligible and therefore little incentive exists to conserve resources or consider downstream impacts. The public nature of water prevents scarcity from greatly affecting the price of goods and services.

It is easy to point to a municipal water bill and suggest that water has cost to the consumer. However, the consumer is actually paying for access to water and changes in water price reflect infrastructure and distribution cost.

The value-flow concept derived by Seyam (2003) illustrates a model for attributing monetary value to water resources. It concludes with a mathematical model to apply value at a certain place at a certain time. In essence, the value flow moves in the opposite direction of water flow and thus accounts for all the indirect uses below any point in the water flow. It also accounts for direct value (such as recreation) and for returning outflows that would create a multiplier effect. By addressing the hydrologic cycle and water use market value, this work 
aimed to provide a valuation scheme for water management that reflects a high resolution of temporal and spatial variations along a water flow. Attributing a monetary value at the source of consumptive use could provide an economic valuation. This monetary value could be extended to include environmental interests at the source of consumption.

Environmental, Social and Economic Perspectives

Water valuation provides the foundation for decision making in water management. Water volume accounting is still important and is a vital component of the valuation scheme. Water's diverse uses raise immediate challenges when attempting quantifying the environmental, social and economic impacts. This section will explore the environmental, social and economic perspectives on water use.

Agriculture is the largest water consumer globally, so a great deal of attention has been given to virtual water trade and water footprinting of agricultural products (Chapagain, 2008; Hoekstra, 2009). By quantifying water use in agriculture and tracing the virtual flow paths, a picture emerges of water use efficiency and of trade patterns relying on water intensive products. Conclusions on efficiency are the first to emerge. By efficiently using water resources there is opportunity to reduce water stress that results in economic 
instability, social health concerns, and environmental degradation. Reducing water consumption or water stress factors is sometimes referred to as water saving. But water savings is a misleading term and best applies to local scarcity. Global water saving is irrelevant because water is quantitatively constant in the hydrological cycle. The term water use efficiency is more appropriately applied than savings.

How important is water use efficiency? Consider data on crop water productivity is wheat (considered a cereal crop). Water productivity is generally higher in the major food exporting countries than in the importing countries. In Figure 4 the crop water productivity (cwp) for wheat is reported across the globe. Think of this as crop per drop. Figure 4 was derived from integrating GIS (geographic information system) with a crop growth model that allowed high spatial resolution for crop water productivity simulation. 
Crop Water Productivity of Wheat (2000)

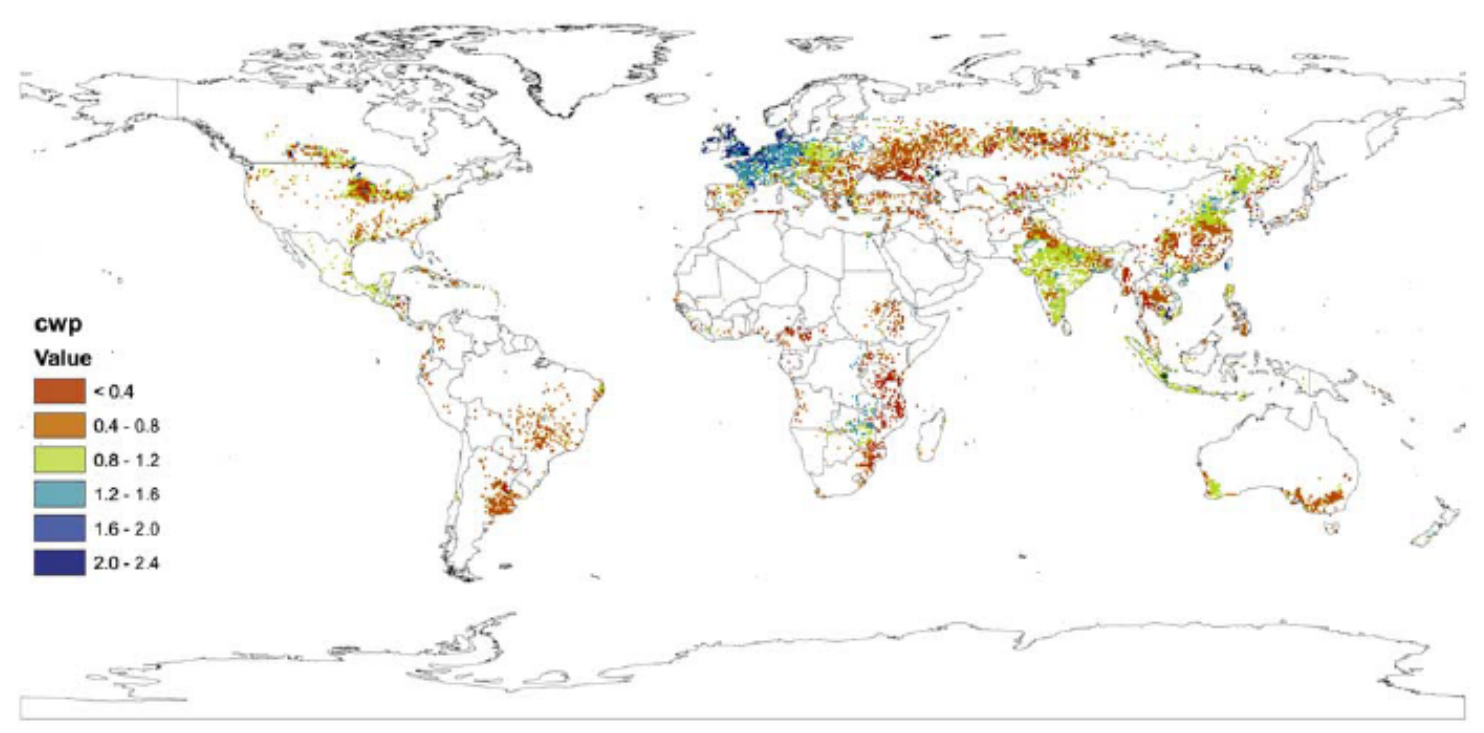

$\uparrow$

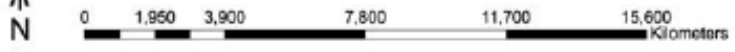

Figure (2) Crop water productivity (cwp) simulated for wheat in 2000. Adapted from Yang, 2007.

As the crop water productivity increases (more crop per drop) the color

scheme shifts from red to blue. As expected for a water intensive crop like

wheat, water scarce regions of the world like East Africa and parts of the Middle

East appear red. When crop water productivity is low, it is more efficient to shift water resources to other consumptive uses and import crops like wheat that would otherwise place stress on the local water resources. A high crop water productivity may bring additional problems as high cwp is often attributed to the use of chemical fertilizer and pesticides that wash into water reservoirs to become a major environmental concern (Yang, 2007). 


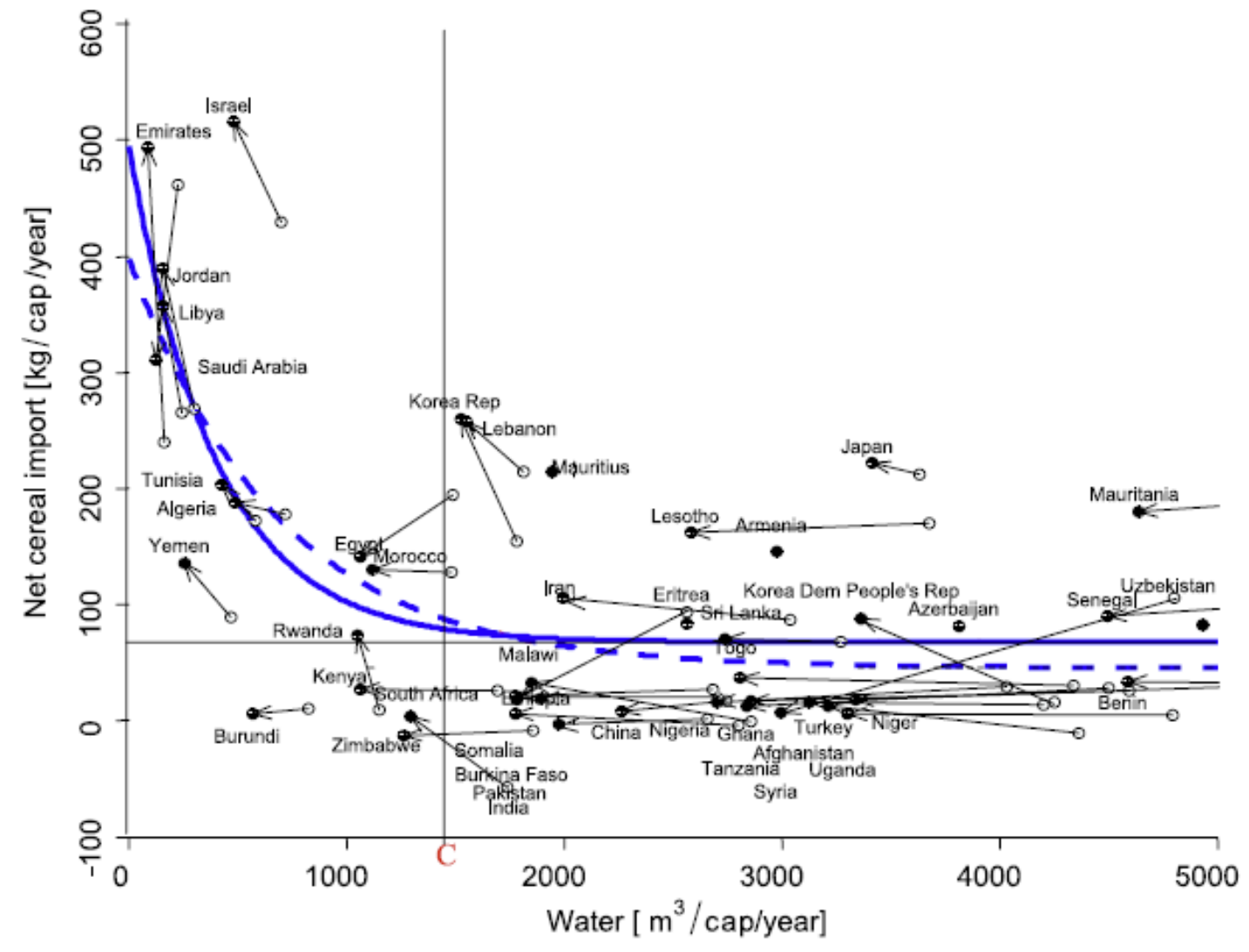

Figure (3) Dependence on cereal imports as a function of water availability in volume per capita. Dashed curve to open circles, data period 1980-1984. Solid curve to solid circles, data period 19962000. Parameter $C$ is the point at which a significant dependence exists between net cereal import and water resources availability. Adapted from Yang, 2007.

Over the course of twenty years, many water scarce countries have experience a reduction in water available per capita, Fig. 3. Greater cereal import per capita is consistent with countries of low crop water productivity. Between the data periods 1980-1984 (open circles) to 1996-2000 (solid circles) countries listed in Fig. 3 demonstrate reduced water availability and shift, indicated by arrows, towards point $C$ where net cereal imports rise quickly. Rapid reductions in water availability, paired with poor crop water productivity (or generally poor 
water use efficiency), has profound implications for social impact, economic instability, trade dependence and ecosystem destruction.

\section{Environmental}

Human water consumption for health, agriculture and industry diverts water from the natural flow and "competes with water for the environment with the potential to negatively impact aquatic biodiversity, riparian health" (p113, Ridoutt, 2010). In consumptive use, both water volume and water quality influences ecosystem health. The grey water component of water footprinting uses water quality indices for effluent or return flow volumes required for dilution. Why not extend a quality index to blue and green water use? Water footprints are certainly a starting point for an analysis of the responsibilities and mechanisms that could possibly mitigate the environmental problems concerning consumptive water use. But to move beyond starting points, the combination of water footprint's strengths with an environmental value assessment can benefit the

Social

Water is necessary for human survival and is the foundation for building strong communities, business and infrastructure around access to fresh water supply. Providing access to water services is usually reserved for governments 
by maintaining the public good through subsidies, quality regulations and resource management. "The appropriation of blue water into agri-food product life cycles is generally not the reason why people lack safe water for drinking and adequate water for sanitation... but by lack of access to adequate water services. "Malnutrition is a more likely impact of blue water consumption, in particular in developing nations where shortage of irrigation water may limit subsistence food production" (p115, Ridoutt, 2010). According to the World Health Organization (WHO) about 1.1 billion people lack access to safe drinking and sanitation sources. As a result, WHO describes the following consequences:

- 1.6 million people die every year from diarrhoeal diseases (including cholera) attributable to lack of access to safe drinking water and basic sanitation and $90 \%$ of these are children under 5, mostly in developing countries;

- 160 million people are infected with schistosomiasis causing tens of thousands of deaths yearly; 500 million people are at risk of trachoma from which 146 million are threatened by blindness and 6 million are visually impaired;

- intestinal helminths (ascariasis, trichuriasis and hookworm infection) are plaguing the developing world due to inadequate drinking water, sanitation and hygiene with 133 million suffering from high intensity intestinal helminths infections; there are around 1.5 million cases of clinical hepatitis A every year.

(Source: WHO http://www.who.int/water_sanitation_health/mdg1/en/index.html) 
Safe drinking water and sanitation is defined by $\mathrm{WHO}$ as:

- Drinking water is water used for domestic purposes, drinking, cooking and personal hygiene;

- Access to drinking water means that the source is less than 1 kilometer away from its place of use and that it is possible to reliably obtain at least 20 litres per member of a household per day;

- Safe drinking water is water with microbial, chemical and physical characteristics that meet WHO guidelines or national standards on drinking water quality;

- Access to safe drinking water is the proportion of people using improved drinking water sources: household connection; public standpipe; borehole; protected dug well; protected spring; rainwater.

(Source: WHO http://www.who.int/water_sanitation_health/mdg1/en/index.html)

While blue water consumption by industry and agriculture is more likely a cause of malnutrition as opposed to reduced access to potable water in, it is still important to understand that global water trade and water management through governance can alleviate some of the social challenges regarding access to water. Water footprinting with impact assessment is important for understanding how water use efficiency will be defined. This may be illustrated by the social challenges resulting from consumptive use, environmental or economic impacts. The challenges for water access are far more complex than what an impact assessment can accomplish alone, but impact assessment can provide the tool for comparing water use efficiency that may improve social ills. 


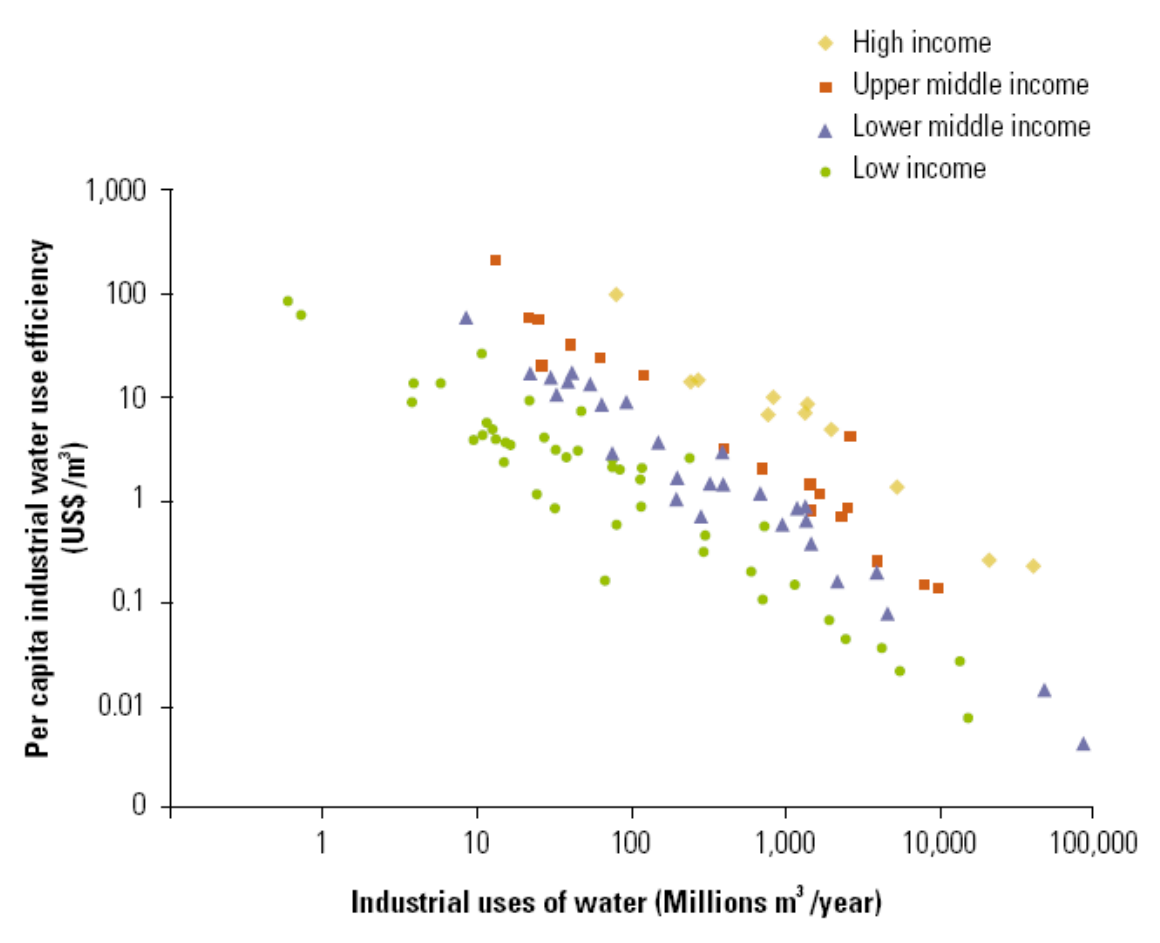

Figure (4) Industrial water use efficiency per capita as measured by economic value added compared to industrial water use in volume per year. UNIDO (2003)

Figure 4 describes the per capita industrial water use efficiency in US dollars per volume as a function of industrial use of water. Per capita industrial water efficiency is calculated as the ratio between country Industrial Value Added (IVA) and the volume of water withdrawn by industry and country total population (in millions). While Industrial Value Added data refer to the year 1999, the total annual freshwater withdrawal refers to any year from 1980 to 1999 and the published industrial shares are mostly estimated for 1987 and population data are estimated for 1999. An income class relationship illustrates that at any given water use volume, the industrial water use efficiency increases with 
increasing income class. The second observation is that within all incomes, the water use efficiency decreases with increasing industrial consumption. These observations are important to the social implications concerning type of water use and corresponding water use efficiency.

In addition, "the most common criticism is that the poor countries cannot afford virtual water import and virtual water import makes the receiving country dependent upon the international market" (p9, Yang, 2007). This could exacerbate the effects of food and water security by relying on trade and placing some nations and communities in political obligations and increasing tension and conflict potential (Warner, 2007). The scale and nature of dependency and potential conflicts will have very different social and economic impacts in different political economies in ways that are, as yet, poorly understood (Warner, 2007).

Yang (p9, 2007) counters criticism by saying that water footprinting "by its origin, describes the fact that many water scarce countries are importing (although often unconsciously) a large portion of their food which has effectively and silently reduced the domestic water demand for food production that otherwise would be needed." However, criticisms that water footprinting is insufficient in maximizing social benefits from policy implications, are accurate (Yang, 2007). Policy making is a multifaceted approach and water footprints 
may play an influential and beneficial role but they are not a singular guide.

In addition, imports may disrupt domestic agriculture markets which cannot produce as cheaply as global producers. Shifting from food production to food import is not without social consequences as Egypt found when it offered food coupons to urbanites for imported food stocks and, as a result, rural political tension increased as farmers could no longer provide a living and urban populations grew rapidly (Roth, 2008).

In terms of efficiency, global water trade may seem ideal, but there is still the human impact that is concerning. A challenge remains to address social impact when evaluating best practices. "The water may well be characterized as virtual but the affected people and politics are very real" (p13, Warner, 2007). This raises the question over political involvement in the first place as opposed to letting markets play out. The answer is simple. Water is a political good and it affects bargaining position amongst various interest groups that influence policy (Roth, 2008). As previously stated, governments are usually the sole investor in water access infrastructure to reduce citizens' transaction costs, meet water needs and keep fighting for survival from emerging. Ideally this is a benign involvement. But according to Roth (2008) controlling resources as political capital is a way to control a state's constituents. City growth through municipal water supplies and irrigation to supply food needs ensures a productive tax base 
and diversifies national political economies that are more adaptive to market scarcities and improves leverage in global markets (Roth, 2008).

In conclusion, water footprinting as an assessment tool may provide insight on water management strategy by evaluating the social impacts for growing nations and industries by pursuing ways to consciously and efficiently utilize the internal and external water resources to mitigate local or national water scarcity without dependency and conflict issues

\section{Economic}

International trade theory suggests that profit is sought through trade between products that are produced with relatively abundant resources in one location in exchange for products requiring scarce resources from the same location (Hoekstra, 2008). Economists use this theory to suggest a savings scheme by reallocation of blue water resources from low beneficial uses to high beneficial uses. However, strategies for shifting from low water use efficiency to high water use efficiency must also be "assessed against other alternatives and factors relating to natural, socioeconomic, environmental and political conditions" (p7, Yang, 2009). These conditions illustrate the complex interests involved in implementing beneficial use management. First, a metric for weighing beneficial uses is required and, secondly, reallocation between water 
uses is not always feasible as a result of local infrastructure, transferability and market gaps. For example, when a beneficial use metric is applied, the recommendations typically encourage a shift from agricultural to industrial or domestic uses. However, recall from chapter one that green water is not transferable. Blue water in irrigation may be reallocated to industry with higher beneficial use, but industry requires other additional infrastructure components that may not be available. Investment to shift resources and build infrastructure is weighed economically against importing virtual water in goods. Most often, virtual water trade wins but according to Yang (2007) virtual water import has not netted a blue water savings in water scarce countries. It did produce nutritional advantages in accordance with Ridoutt's (2008) conclusion that malnutrition is a result of a lack of irrigation available for local food crops. Yang (2007) suggests that an influx of foreign goods may also suppress the domestic efforts to mobilize efficiency and again, from Hoekstra (2008), the globalization of freshwater risks dependency on the import of water-intensive goods. Water resources, like most goods and services, are consumed from the local to global scale through supply and management. It is therefore not unreasonable to respond to water management and access up to a global scale through a quantitative value added management scheme. Many economist expressed concern about the language of 'virtual water trade' (part of water footprints) 
claiming that there was only real water and virtual water is just food trade (Yang, 2007). It is true that we trade tomatoes and not the volume of water associated with producing the tomatoes. In response, most publications recommend replacing virtual water trade with virtual water transfer or virtual water flow when water is not the commodity traded. The water used in production has very little effect on product cost and associated environmental and social impact. This illustrates two points when it comes to the adoption of global water management. First, water use may be deemed environmentally or socially adverse and therefore regulated in global markets just as chemicals such as lead and arsenic. Secondly, according to the Heckscher-Ohlin theory, international trade is regulated in accordance with comparative cost advantages. Since water prices either do not exist or are greatly subsidized there is no direct monetary cost calculation available. Instead of markets relying on comparative cost advantages, they rely on water scarcity. "If an economically appropriate value was attached to water or to its supply, there would be no need for a virtual water trade strategy under a special promoting policy because trade would regulate itself in accordance with comparative cost advantages" (p9, Yang, 2007). Seyam (2003), a paper with Hoekstra, devised a strategy to apply monetary value to water by tracking the flow of economic applications as a reverse direction of 
stream flow. A concept like this may encourage markets with real comparative cost advantages.

\section{Universality}

Chapter one introduced assessment boundaries for water footprinting. The importance of considering these boundaries is in the variable calculations that may result from differing approaches. While recommendations for what to calculate are being addressed (Hoekstra, 2009), how to report water footprints in a useful and universally comparable standard is a current challenge (Ridoutt, 2010; Milà, 2009; Pfister 2009; Ridoutt, 2009, Warner, 2007) The unique nature of water resources as renewable at various rates, variable in space, transient, costly to store, industrially valuable and finally a human necessity makes water one of the most versatile resources on earth and therefore very difficult to assess. However, tools have been developed in the past thirty years to respond to manufacturing standards and environmental impact assessment that may be beneficial to a value added water management scheme. There is a priority among water footprint practitioners is to form agreement on impact categories concerning freshwater consumption and to develop common characterization models and factors. Ridoutt (2009) recommends that these model and factors be consistent with developments in life cycle impact assessment. 
Clear goals, like Ridoutt's (2009), to protect freshwater ecosystems and avoid of fossil groundwater depletion through impact pathways help to define specific courses of action in the effort to increase water use efficiency. While Ridoutt's is an environmentally focused goal, the environment is tied to economic and social prosperity and are, by extension, positively affected by improvements in environmental attention. Characterization factors for a clearly defined goal help achieve normalized values that are important for measuring the unique nature of water between various uses. Instead of trying to tackle everything in a complex system, a specific goal provides strong value and direction towards solutions.

One such specific example from Ridoutt (2009) identifies methods for reducing water footprints that include:

o Reducing the sourcing of agricultural ingredients from locations with high environmental water stress which depend on irrigation for crop production

o Reducing the sourcing of agricultural ingredients from locations or operations that depend on large quantities of irrigation water per unit of production;

o Encouraging investments in farming systems which increase the efficiency of irrigation water use and decrease runoff and leaching of agrichemicals;

o Encouraging investments in industry to improve water use efficiency, water reuse and recycling, and wastewater reduction and treatment; 
o Influencing the location of new factories away from locations where renewable freshwater resources are scarce;

o Shifting production away from consumption of non-renewable blue water resources.

Specific goals reduce the scope of interests involved, but result in a far more manageable approach. I have introduced the environmental, social, economic and political interests in water resource to establish the consequences for poor water management.

In chapter five I will introduce Life Cycle Assessment, a well established method for assessing environmental impacts of a product. The framework and wide adoption of LCA is championed as a strong agent to advancing the water footprinting concept for water management strategies. 


\section{Understanding Life Cycle Assessment}

“Life cycle assessment is a compilation and evaluation, according to a systematic set of procedures, of the inputs and outputs of materials and energy and the associated environmental impacts directly attributable to the function of a product throughout its life cycle." (ISO 14040)

\section{History}

The first rigorus scientific investigations of material resource consumption and energy efficiency date back to the 1960s from concerns over a scenaro of a rapidly increasing global population and industrial development with limited natural resources and fossil fuels. Studies on environmental issues and production-consumption systems grew in popularity in this period with the first major inventory analysis of resources and waste was performed on behalf of the Coca-Cola Company and focused large on containers and packaging (Guidice, 2006; Hundal, 2002). The oil crisis of early 1970s encouraged audits of energy and resource efficiency and emergence of methodologies such as Resources and Environmental Profile Analysis (REPA) in the US and Ecobalance in Europe 
(Guidice, 2006). These programs raised questions about limited information on the environmental impacts of emissions.

A new perspective emerged to view industrial production systems holistically from the path of raw material extraction to transformation, consumption, and end of life (or grave phase) as post consumptive waste. The result of a holistic approach informs every step of the production-consumption system for efficiency and environmental impact. With this approach, impacts cannot be simply moved to another location or time to "clean" up an industry and the production phases become more transparent. As the oil crisis subsided in the early 1980's, the production-consumption system evaluation focused largely on energy efficiency in industrial processes and on packaging pollution, in particularly, containers for liquids and drinks (Guidice, 2006). Having a specific purpose facilitated steps by industry, academics, and governments to pursue monitoring and impact assessment. By the end of the 1980's it was clear that common methodologies would help focus the intent and strengthen evaluation reporting. The Society of Environmental Toxicology and Chemistry (SETAC) convened in 1990 as a response to the growing need to recognize standard practices, discussing challenges, and improve validity (Guidice, 2006). It was at this conference that the term Life Cycle Assessment was fist coined and later (1996) adopted by the International Standards Organization as the 14040 
series (Guidice, 2006; Hundal, 2002). In 2002, SETAC was joined by the United Nations Environmental Programme (UNEP) to disseminate and educate about Life Cycle Assessment and environmental impacts, defined as any anthropogenic change to the environment whether beneficial or detrimental.

With a well-defined goal and scope the LCA is a valuable tool for highlighting concerning areas of a system, engineering preventative design, and if used properly can compare impacts of different products and processes. The success of the current environmentally focused LCA has prompted a social impact variation under development with the UNEP/SETAC using current environmental LCA methods (Finnveden, 2009). (UNEP, United Nations Environment Programme; SETAC (Finnveden, 2009).

A strong life cycle assessment starts with a well defined purpose and follows a stringent framework to reduce inconsistencies.

\section{LCA Framework}

A life cycle assessment begins by defining the goal and scope that specifies the purpose of a study. It is in the goal and scope that not all LCA studies are equal. The complexities of production-consumption systems and potential environmental impacts are mitigated through carefully prescribed depth, detail, application and functional units. The goal focuses the study on an 
intended application, motivation and audience while the scope addresses the goal by specifying the function of a product or system, the boundaries for the system and data collection. It is clear that differences in goal and scope can lead to differences in outcome between studies. This is of more concern when comparative studies are undertaken. In such a case, the purpose of a comparative study defines the goal and scope.

Two types of LCA influence the goal and scope; attributional and consequential LCA. "Attributional LCA is defined by its focus on describing the environmentally relevant physical flows to and from a life cycle and its subsystems. Consequential LCA is defined by its aim to describe how environmentally relevant flows will change in response to possible decisions" (Finnveden, 2009). Think of them as descriptive analysis and change-oriented analysis respectively. They are different in goal and scope and in the type of data collection pursued. The two types of data collected are described as average and marginal. Average data is the best approximation of all known environmental impacts from a specified component of the study system. Marginal data reports on the incremental effects due to changes in the output of a specified study system component. It is clear that for consequential LCA, marginal data better informs efforts in decision making on a system. 
After the goal and scope are defined, the life cycle inventory analysis (LCI) can be conducted and involves data collection, calculation and statistical reporting. For new studies, this is an iterative process revealing obstacles, data demands, change in methodology and potential revisions to the goal and scope. Much like the experimental method, an LCI study is as revealing to execution challenges as it is to the potential impacts. In this sense, adoption of efficient and accurate life cycle assessments requires a strong framework, communication between studies and accessible data, similar to the needs of water footprinting. However, unlike water footprinting, LCA achieves these requirements through a quarter century of refinement, industry cooperation and regulatory compliance.

Following the life cycle inventory, an impact assessment evaluates the relevant environmental concerns, the methodology, goal and scope and recommendations for interpretation, forecasting, and decision making. Consider the current debate concerning the degree of environmental impact between paper and plastic shopping bags. Plastic bag use is now outlawed in some cities over public perception of these bags as litter and a negative association with petroleum products. The life cycle assessment tells a different story where paper bags have a greater energy consumption, emissions and volume of waste. 

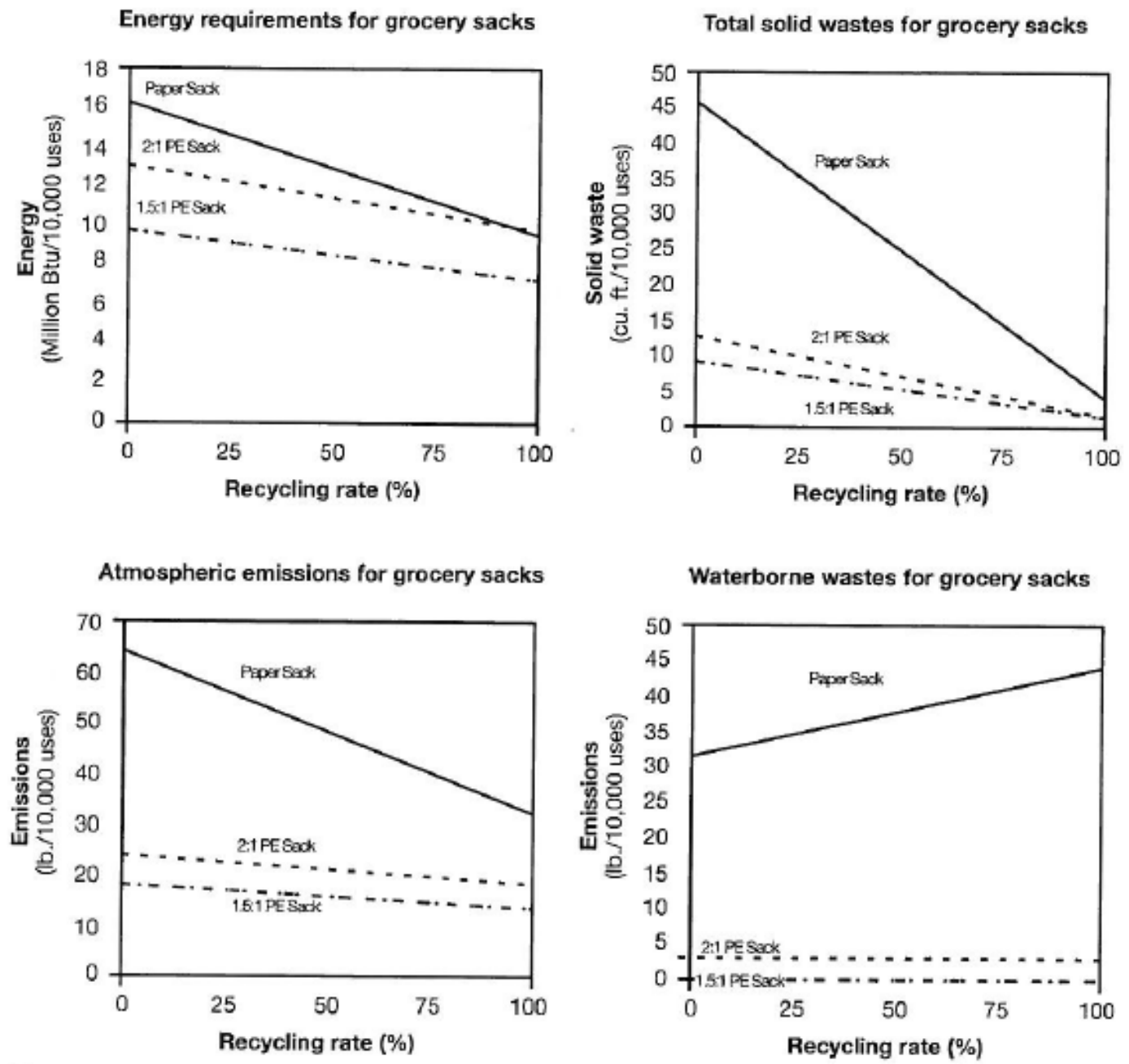

Figure (5) A Life Cycle Assessment between paper and plastic grocery bags revealing the advantages of plastic. (Graedel, 1998; adopted from The Council for Solid Waste Solutions, 1993)

Comparing the manufacturing and disposal stages of paper and plastic sacks reveals that plastic is the far better choice. Biodegradability is not a considerable issue because a top-covered landfill shows no degradation of either product (Graedel, 1998). Instead, recycling as a disposal stage is considered with rates between $0-100 \%$. This study did not evaluate the relative environmental stresses with respect to one another (ie, where was the energy sourced, differing 
impacts of differing solid wastes or airborne emissions). This serves to

illustrate two things; first, a holistic LCA study attempts to objectively evaluate impacts where well defined assessment boundaries and functional units are necessary for comparative studies. Secondly, the LCA study refutes public perception- possibly a much more difficult obstacle to overcome.

\section{Limitations}

While the LCA assessment methodologies are objective, the preliminary assumptions at the base of every LCA (ie. defining the system boundaries, selecting the sources of information and deciding the impact categories to be examined) are all subjective and have a decisive effect on the final results of the assessment (Giudice, 2006; Vezzoli, 2008). Vezzoli (2008) explains that the analysis of life cycles is always more or less about compromise between practicality and complexity and that Life Cycle Assessment is definitely the bestestablished methodology. The strong framework, communication between studies and accessible data in LCA is a result of what Finnveden (2009) describes as harmonization and consensus building based on what, from a scientific point of view, is regarded as the most appropriate choices.

Environmental impact is about the sum of processes and end use of the materials and therefore it is important to consider the broad scope from material 
extraction to disposal. Predicting disposal is a challenge met by product designs encouraged to facilitate desirable practices. In generating the scope of analysis, data availability is a concern, much in the way it is with water footprinting.

The LCA addresses potential environmental impacts and not absolute environmental impacts due to:

The relative expression of potential environmental impacts to a reference unit The integration of environmental data over space and time The inherent uncertainty in modeling of environmental impacts The fact that some possible environmental impacts are clearly future impacts (ISO 14040)

The time at which an event takes place can greatly alter the environmental impact. For example, volatile organic compound (VOCs) combine with nitrogen oxides from automobile exhuast to produce photochemical smog. If VOC emmissions are limited to night hours than the gases often disperse before reacting with morning traffic emissions (Graedel, 1998). Spatial differentiation can equally vary the environmental impact through characteristics of the receiving environment. The loading and response relationship may be nonlinear with regard to an environment's ability to absorb impact based on 
quantity and rate of impact. Together the spatio-temporal evaluation is important if truely comparible values are to be compared. It is clear that many of the boundary and spatio-temporal concerns are similar to water footprinting and also include; geographically varying characteristics of receiving environments and the difficulty comparing different types of effects.

In the impact assessment phase of LCA, the goal of the study may be to compare significance of impacts between systems, as would often be the case in water footprinting. Comparing differing impacts requires weighting but has been met with reluctance in the scientific and engineering community due to the point of view that many values cannot be normalized to indicate, from a scientific perspective, a "right" solution (Finnveden, 2009). "Achieving worldwide agreement on valuation seems unlikely...[however] it is perhaps not so contentious to define the important topics for valuation- treaties on ozone, and global climate changes attest to that" (Graedel, 1998). While weighting is a both challenging and controversial, Finnveden (2009) concludes that weighting methods are achievable through recent developments in environmental economics and he recommends these methods be discussed, evaluated for consistency and applied to new studies for continued review in published literature. Simply because there is not yet a system or agreement does not mean that one cannot exist. 
A final consideration of LCA limitations concerns the impact assessment phase when applied to decision making. When decisions are presented as either/or scenarios they are simple to understand and rationalize the choice. However, broad LCA assessments, beneficial for their scope and data mining, are not always prepared to be presented in either/or scenarios.

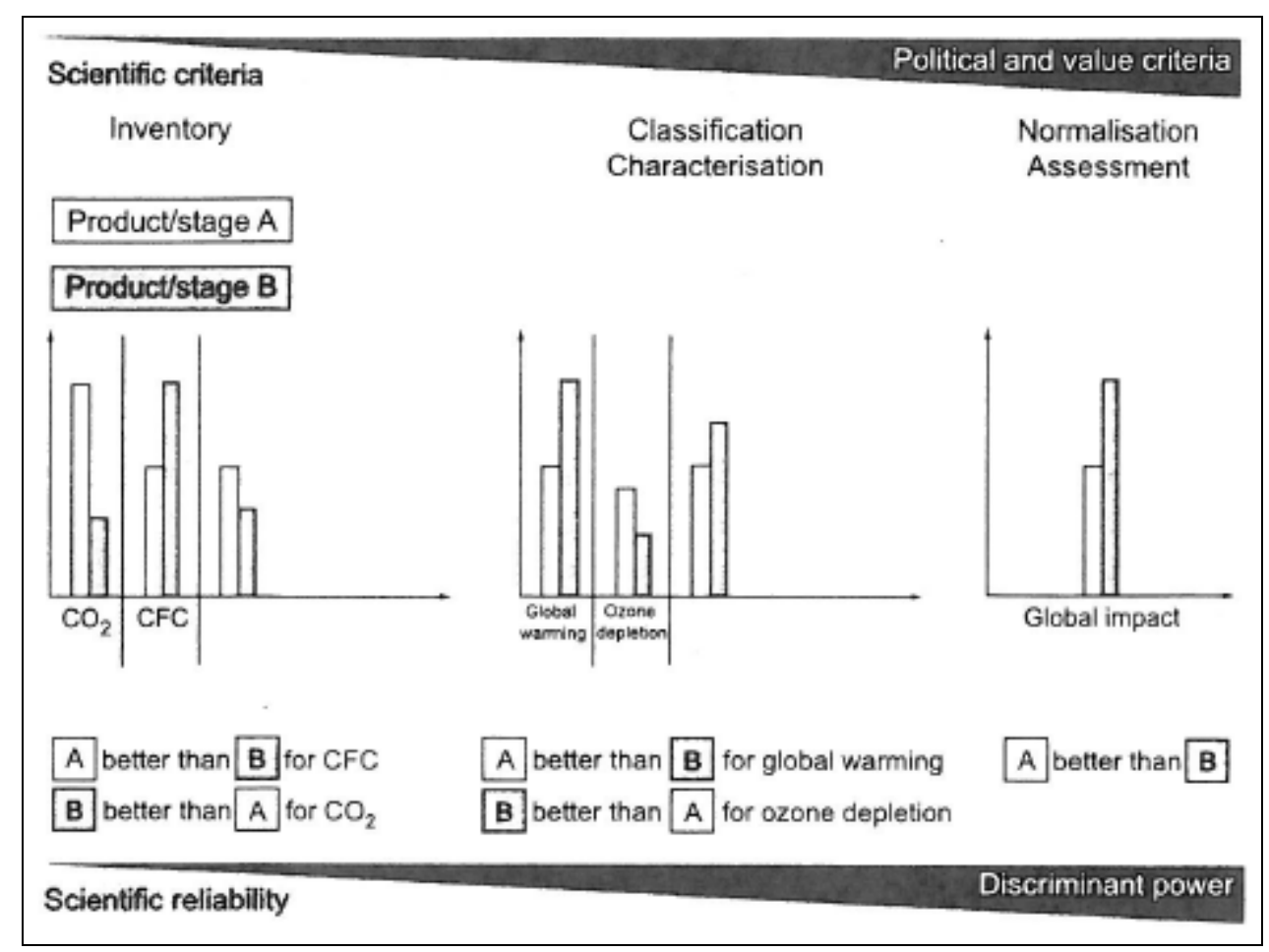

Figure (6) Increasing discriminate value of LCA results often reduces scientific reliability as considerable impacts are normalized to make either or decisions. (Vezzoli, 2008)

The loss of considerable impacts occurs when multiple components and environments are normalized to one index to simplify discriminate decision making. It is simple to select product A from the position of policy or management. However, the complexity of the scientific evaluation demonstrates 
emission, space, and receiving environment variances. This is not a warning against normalized weighting, but rather, as Finnveden (2009) suggests, a need to critically report inconsistencies in weighting by publishing recommendations to overcome these problems.

In conclusion, the LCA's well defined goal and scope, strong scientific attention and expanding data pool prepare it as candidate for improving the water footprint utility. While LCA demonstrates similar issues critical of the water footprinting concept, the LCA community is motivated to improve industrial efficiency, comply with regulation and explore new resources that save the livelihood of businesses, economies, environments and communities. In chapter six I will introduce emerging LCA studies incorporating freshwater resources. I will describe lessons learned from the carbon footprinting concept that may help overcome obstacles to impact assessment with water footprinting. Finally, conclusions from this literature review will be presented with regard to recommendations to the pursuit of a universal water management utility that merges strong characteristics of water footprinting and life cycle assessment. 


\section{Merging Concepts}

In order for water footprinting to be adopted as functional utility, it will need an impact assessment component. However, the founding scholar of water footprinting rejects merging LCA with water footprints under the claim that LCA is not suited for use with water footprints because LCA does not include freshwater in a sufficient way (Hoekstra, 2009). Ridoutt (2009) echoes the sentiment that LCA needs improvement with regard to consumptive freshwater impact and what is more distressing is that industries hardly document consumptive use (Finnveden, 2009). It would be reasonable to strengthen the consumptive component of water impact by incorporating a concept for freshwater consumption like water footprinting.

However, Hoekstra (2009) claims that water footprinting is not complimented by an impact assessment. "The water footprint can best be used solely in its original and well-established meaning, which means it excludes impact," (p81, Hoekstra, 2009). It would seem, in regard to water footprinting challenges and to scientists contributing to value added approaches, that the 
water footprinting network director would be more open to progressing the ideas championed by other scientist in the field of water resources management.

A water volume is meaningless to associate with a scale for reducing use for two reasons. First, the benefit of comparing water volumes is unclear and no definitive objectives have been set that correlate with reduced use (Ridoutt, 2009). Second, volume does not effectively describe environmental, social, and economic cost. Carbon footprinting is acceptable to report as a simple mass because of the credible assumption that more emissions (more normalized mass) respond directly to climate change where the overall goal is reducing emissions.

\section{Appeal of Carbon Footprinting}

The widespread appeal and adoption of carbon footprinting is a result of intuitive application. Carbon footprints work because they report greenhouse gas emission as normalized carbon equivalents. It is simple to understand that larger carbon footprint have a larger deleterious consequences on global climate. Water footprinting does not produce the same correlation between quantity and impact. This universality provides meaningful comparison between business, products and consumers. Ridoutt (p5, 2009) describes the major difference between carbon footprinting and water footprinting and why the latter fails to make comparable assessments: 
"The major dissimilarity between product carbon and water footprinting is that the latter does not currently use characterization factors to arrive at a normalized value which is comparable from one product to another. Due to the similarity in name between carbon and water footprinting, we argue that water footprinting should have a similar conceptual foundation to carbon footprinting which is already in widespread use. This will avoid stakeholder confusion and maximize the potential of water footprinting as a driver for sustainable consumption and production. Current approaches to water footprinting need to be revised because a simple summation of different forms of water consumption sourced from different locations is potentially misleading, is not comparable from one product or service to another, and does not represent a clear relationship to environmental or social impact."

Water use impacts are inherently variable between location, time, type of freshwater consumption and of the corresponding opportunity costs and impacts of consumption. Green house gases are considered to have the same impact regardless of location and it is simple for consumers and business to connect environment and social impacts to lifestyle behaviors. Businesses are keen to the issues of freshwater scarcity and reduced impacts, but are understandably concerned about water footprint shortcomings and misinterpretation. To start, there is no target consumption, or trade allocation of water resources unlike carbon emissions. Water use and transfer is complex and saving water does not necessarily offset an impact or become transferable (like a carbon credit). 
LCA advances in freshwater consideration

Only in recent years has freshwater consumption been actively considered for LCA. Impact expressed in terms of quantity (scarcity) and quality (degradation), or in potable water normalization, or by regionalized water resource availability are all considerable methods for introducing a standard measure (Finnveden, 2009). Consumptive water use cannot easily rely on aggregated global data because many water use related impacts are specific to the catchment scale; availability, infrastructure, ecological conditions, consumption patterns (Cooney, 2009).

I have described how the water footprint concept evolved independently from life cycle assessment and does not exhibit impact assessment in the footprint report. It is impossible to know how a volumetric report relates to impact and as a result the water footprint is approached with reservations from industry and management. Pfister (2009) and Ridoutt (2010) are the most recent comprehensive studies on producing an impact assessment for water use. Ridoutt (2010) recommends incorporating a water stress characterization while Pfister (2009) uses damage indices for human health (WHO disability-adjusted life year) ecosystem quality (potentially disappeared fraction of species (PDF) by the Eco-indicator 99 method) and damage to resources (EI99 surplus energy). 
Both studies recognize the need for regional specific reporting but with globally comparable values through weighting and normalization factors. Advances in LCA demonstrate that there is a considerable push by scientists and businesses to adopt water resources management in a global utility.

\section{Conclusions}

Interest in water use impact, in both withdraw sources and end of use locations, has generated contributions to the potential LCA adoption of wateruse reporting. Research from the water footprinting concept could be greatly beneficial to data collection, understanding challenges and knowledge of trade and political influences. However, cooperation from the water footprint community appears limited and in some cases ignored completely.

\section{Normalized values}

While weighting is a both challenging and controversial, Finnveden (2009) concludes that weighting methods are achievable through recent developments in environmental economics and he recommends these methods be discusses, evaluated for consistency and applied to new studies for continued review in published literature. Within water footprinting applications, this paper agrees with weighting methods for normalizing water use impact in a global arena. 
I concede that the utopian notion of a universally agreeable best practice is unrealistic. Universality is demonstrated to be a complex and sometimes conflicting issue were agreement is unlikely. However, I take the perspective that we don't have to agree. Policy and regulation is easily prescribed without meeting universal agreement. Democratized governance is an excellent example. One should also consider platforms such as LEAD (C) and EnergyStar (C) that promote energy reduction and sustainability practices. These programs work on a voluntary basis, but succeed due to real demand. Demand on water resources will require similar forward thinking initiatives and a voluntary platform may be all that is required to gain momentum for better practices.

One way to normalize values that consider regionally specific characteristics is to introduce a water stress component of the water footprint. Water stress can be associated with scarcity or degradation by an imposed standard. Water stress has been documented in the literature as a more revealing indicator of water consumption environmental and social impact (Ridoutt, 2010). A second way to normalize values is through adjusted values for lifeexpectancy or species death. Such concepts are used by the World Health Organization, known as the disability-adjusted life year and the Potentially Disappeared Fraction of species (PDF) by the Eco-indicator 99 method (a damage oriented method of LCA for ecosystem quality) (Cooney, 2009). 
The suggestion to move to a quantifiable water impact assessment can provide better water management practices from the local to global scales. An assessment can start the conversation for best practices, as it provides a platform for evaluating conditions against desirable outcomes. As for designing policy measures, there may be pitfalls to the interference of policy makers and governance at the global trade level where there is potentially less focus on people (Warner, 2007).

\section{Intuitive consumer function}

While the utility of the water footprint need further refinement, it is still important to address the potential for adoption by the public. Concepts that are simple to understand and intuitive in function, like carbon footprints, may garner public support. Behavioral changes and advocacy can have a powerful effect on the spread of a concept.

\section{Investing in Science}

It is imperative that the pursuit of science be encouraged to increase understanding of the natural environment and the anthropogenic influences on environment. It is critical that political and social sciences not be impeded in understanding the complexities of economic growth and development, technological influences, social behaviors and environmental dependencies. 
Improving the designed environment

We stand at the beginning of the $21^{\text {st }}$ century with monstrous social and environmental challenges at the global scale. There is an increasing need to account for water use and the subsequent impacts. It should be expected that civilization can produce the tools and collective cooperation to design a society that eliminates social and environmental degradation. At a time in human history when we are capable of almost anything, I hope that we will responsibly, I dare say dutifully, face humanities greatest challenges. 


\section{References}

Allan, J. A. (1996) Policy responses to the closure of water resources:

regional and global issue, in water policy: allocation and management in practice. Chapman and Hall, London.

Bras, B. (1997) Incorporating environmental issues in product design and realization. Industry and Environment, Special Issue on Product Design and the Environment, (UNEP/IE): 20

Canals, L. M., Chenoweth, J., Chapagain, A., Orr, S., Antón, A. and Clift, R. (2009) Assessing freshwater use impacts in LCA: Part I-inventory modelling and characterisation factors for the main impact pathways. Journal of Life Cycle Assessment 14: 1, 28-42.

Chapagain, A.K., Hoekstra, Y. A. (2008) The global component of freshwater demand and supply: an assessment of virtual water flows between nation as a result of trade in agricultural and industrial products. Water International 33: 1, 19-32.

Chapman, J. (2005) Emotionally durable design. Earthscan. Camden High Street, London.

Cooney, C. (2009) LCA finally takes water into account. Environmental Science and Technology 6: 3986.

Finnveden, G. et al. (2009) Recent developments in life cycle assessment. Journal of Environmental Management 91. 1-21.

Giudice, F., La Rosa, G., Risitano, A. (2006) Product design for the environment: a life cycle approach. Boca Raton, Florida: CRC Press Taylor and Francis Group.

Graedel, T.E. (1998) Streamlined life-cycle assessment. Upper Saddle River, New Jersey: Prentice Hall.

Hoekstra, A. Y., Chapagain, A. K. (2007) Water footprints of nations: Water use by people as a function of their consumption pattern. Water Resources Management 21: 1, 35- 48. 
Hoekstra, A.Y., Chapagain, A.K., Aldaya, M.M., Mekonnen, M.M. (2009) Water Footprint Manual; State of the Art 2009. Water Footprint Network, Enschende, The Netherlands.

Hundal, M.S. (2002) Mechanical life cycle handbook: good environmental design and manufacturing. New York, New York: Marcel Dekker, Inc.

ISO 14040 (2006) Environmental management- Life Cycle Assessment- Principles and framework.

http://www.iso.org/iso/iso catalogue/catalogue tc/catalogue detail.htm?csnumb $\underline{\mathrm{er}=37456}$

Krut, R. \& Gleckman, H. (1998) ISO 14001 A missed opportunity for sustainable global industrial development. London, UK: Earthscan Publications Ltd.

Lebel, L., Lorek, S. (2008) Enabling sustainable production-consumption systems. Annual Review of Environmental Resourses 33: 241-275

O'Rourke, K.H., Williamson, J.G. (2000) When did globalization begin? National Bureau of Economic Research. 1050 Massachusetts Avenue Cambridge, MA 02138 http://www.nber.org/papers/w7632

Pearce, F. (2008, June) Virtual Water. Forbes. Retrieved from http://www.forbes.com/2008/06/19/water-food-trade-tech-water08cx fp 0619virtual.html

Pfister, S., Koehler, A. and Hellweg, S. (2009) Assessing the environmental impacts of freshwater consumption in LCA. Environmental Science and Technology 43: 4098-4104.

Ridoutt, B.G., Eady, S.J., Sellahewa, J., Simons, L., Bektash R. (2009) Product water footprinting: How transferable are the concepts from carbon footprinting? $6^{\text {th }}$ Australian Conference on Life Cycle Assessment, February 16 ${ }^{\text {th }}, 2009$.

Ridoutt, B.G., Eady, S.J., Sellahewa, J., Simons, L. and Bektash, R. (2009) Water footprinting at the product brand level: case study and future challenges. Journal of Cleaner Production 17: 13, 1228-1235. 
Ridout, B.G., Pfister, S. (2010) A revised approach to water footprinting to make transparent the impacts of consumption and production on global freshwater scarcity. Global Environmental Change 20: 113-120.

Roth, D., Warner, J. (2008) Virtual water: virtuous impact? The unsteady state of virtual water. Agriculture and Human Values. 25: 257-270.

Seyam, I.M., Hoekstra, A.Y., Savenije, H.H.G. (2003) The water value flow concept. Physics and Chemistry of the Earth 28: 175-182.

UNIDO (United Nations Industrial Development Organization) (2003) Promoting cleaner industry for everyone's benefit. Collaborating agencies: WHO (World Health Organization) UNDESA (United Nations Department of Economic and Social Affairs) http://unesdoc.unesco.org/images/0012/001295/129556e.pdf

UNESCO (2003) Executive Summary of the world water development report. Water for people, water for life. www.unesco.org/water/wwap

UNESCO World Water Development Figure on Water conflict. Accessed April 2010. http://www.unesco.org/water/wwap/facts figures/sharing_waters.shtml

Vezzoli, C. and Manzini, E. (2008) Design for environmental sustainability. London, England: Springer-Verlag London Limited.

Warner, J.F. and Johnson, C.L. (2007) 'Virtual Water' - Real people: useful concept or prescriptive tool? Water International 32: 63-77.

WFN (Water Footprint Network Mission) http://www.waterfootprint.org/?page=files/WFN-mission

WHO. Health through safe drinking water and basic sanitation. http://www.who.int/water sanitation health/mdg1/en/index.html

Yang, H., Zehnder, A. (2007) "Virtual Water": An unfolding concept in integrated water resources management. Water Resources Research 43: W12301. 